\title{
Evaluation of Transmural Myocardial Perfusion by Ultra- Harmonic Myocardial Contrast Echocardiography in Reperfused Acute Myocardial Infarction
}

\author{
Hiroshi Wada, MD; Takanori Yasu, MD; Hiroyuki Kotsuka, BS; Yuhki Hayakawa, BS; \\ Yoshiaki Tsukamoto, MD; Nobuhiko Kobayashi, MD; \\ Takeshi Ishida, MD; Yasuyuki Kobayashi, MD; Norifumi Kubo, MD; \\ Masanobu Kawakami, MD; Muneyasu Saito, MD
}

\begin{abstract}
Background The transmural distribution of myocardial perfusion is important for predicting the contractile reverse of an infarcted wall in reperfused acute myocardial infarction (AMI). Evaluating transmural myocardial perfusion by myocardial contrast echocardiography (MCE) could predict the long-term recovery of left ventricu$\operatorname{lar}(\mathrm{LV})$ function.

Methods and Results The study group comprised 20 consecutive patients with a first-episode anterior AMI with total occlusion of the proximal left anterior descending artery, who underwent successful percutaneous coronary intervention within $24 \mathrm{~h}$ of onset. MCE was performed on the 15 th day after the onset, using ultraharmonic gray-scale imaging with intermittent end-systolic triggering every 4 beats or every 6 beats. Regions of interest were placed over both the endocardial and epicardial region at the mid-septal level. Regional wall motion (RWM) of the infarcted anterior wall and global LV function were assessed by 2-dimensional echocardiography and left ventriculography in both the acute and chronic phase. The transmural distribution of myocardial perfusion by MCE demonstrated a significant relation with RWM score index $(r=0.75, p=0.0004)$. Recovery of RWM and LV ejection fraction (LVEF) at 6 months after reperfusion was significantly greater in the group with good perfusion of the epicardium according to MCE than in the poor perfusion group [RWM (SD/cord); $-1.23 \pm 0.91$ vs $-3.51 \pm 0.84, \mathrm{p}=0.001, \operatorname{LVEF}(\%) ; 63.8 \pm 10.4$ vs $47.0 \pm 3.4$, $\mathrm{p}=0.04]$.
\end{abstract}

Conclusions Assessing the transmural distribution of myocardial perfusion by MCE can predict the long-term recovery of LV function after a reperfused AMI. (Circ J 2005; 69: 1041-1046)

Key Words: Acute myocardial infarction; Computed tomography; Contrast echocardiography; Myocardial perfusion

A pproximately $20-35 \%$ of angiographically successful recanalizations of the infarct-related artery in patients with acute myocardial infarction (AMI) fail to salvage ischemic myocardium because of a discrepancy between an open epicardial coronary artery and no blood flow in the damaged distal microvessels!-4 Regions with no-reflow show no improvement in regional function over time despite recanalization of the epicardial coronary vessels. These patients also have poorer global left ventricular (LV) systolic function, malignant ventricular arrhythmias, intractable congestive heart failure, progressive LV remodeling, cardiac rupture, and higher mortality 2,3,5,6

Bogaert et al reported that functional recovery of viable subepicardial tissue is a mechanism of late improvement in the regional and global LV fraction after a so-called transmural myocardial infarction (MI)? Furthermore, our recent

(Received March 1, 2005; revised manuscript received May 23, 2005; accepted June 28, 2005)

First Department of Integrated Medicine, Omiya Medical Center, Jichi Medical School, Saitama, Japan

An abstract of this work was presented at the 75th annual scientific session of the American College of Cardiology on March 16th, 2002. Mailing address: Takanori Yasu, MD, The Cardiovasular Division, First Department of Integrated Medicine, Omiya Medical Center, Jichi Medical School, 1-847 Amanuma, Saitama, Saitama 330-8503,

Japan. E-mail: tyasu@omiya.jichi.ac.jp study in patients with AMI showed that assessing the microcirculation in the transmural myocardial layers by multidetector computed tomography (MDCT) predicted progressive LV remodeling and the long-term recovery in contraction? Myocardial contrast echocardiography (MCE) has been proposed as a powerful modality for assessing transmural myocardial perfusion, on the basis of bedside safely, economy and repeated performance compared with other imaging modalities, because of its superior resolution in time and space without exposure to radiation?-14 The aims of the present study were to assess transmural myocardial perfusion by MCE and compare the results with those of MDCT and to determine whether MCE can predict the long-term recovery of LV function in patients with AMI.

\section{Methods}

\section{Patient Population}

Twenty patients who had experienced their first anterior AMI during the period 2001 to 2002, had total occlusion (TIMI 0) of the proximal left anterior descending artery (LAD) and who had undergone successful balloon reperfusion therapy (TIMI 3 ) within $24 \mathrm{~h}$ of onset were investigated. The average age was $66 \pm 13$ years, the male:female ratio was $17: 3$, the average maximum creatine kinase was $2,509 \pm 2,003 \mathrm{IU} / \mathrm{ml}$. None showed collateral flow to the 
a

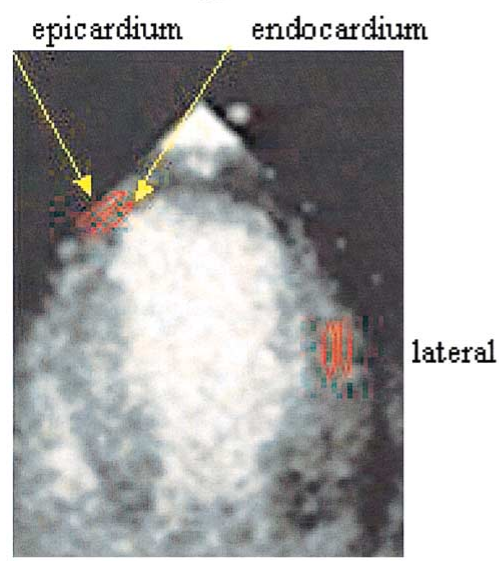

b

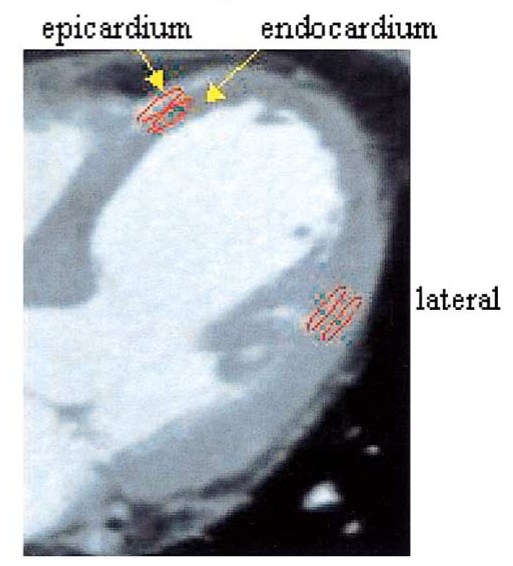

Fig 1. Region of interest (ROI) placed over the epicardial and endocardial half of the infarct midseptum and the non-infracted mid-lateral wall for (a) MCE and (b) MDCT.

a

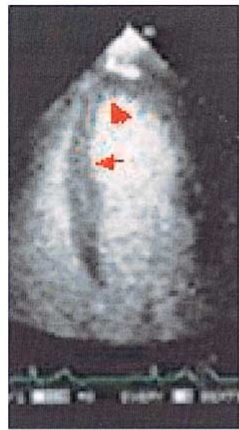

Epicardium: good Endocardium: good

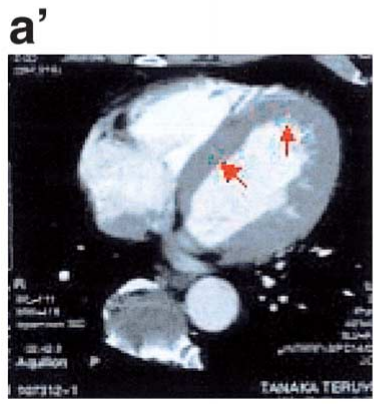

Epicarisim: good Erdocardinn: good b

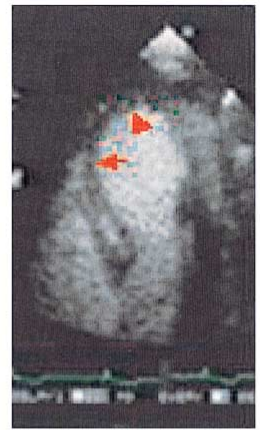

Epicardium: good Endocardium: fair

b'

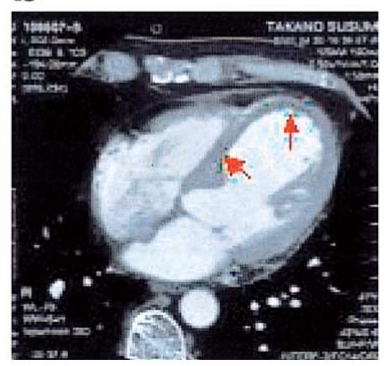

Epicardinn: good Erdocardim: fai

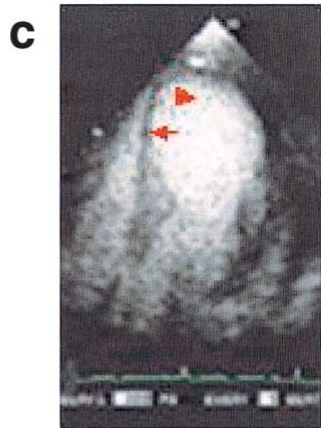

Epicardium: poor Endocardiutn: poor

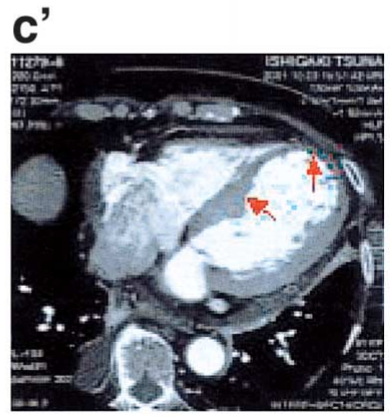

Epicardinn: poor Frdocardim: poor

Fig 2. Representative images from MCE $(a-c)$ and MDCT $\left(a^{\prime}-c^{\prime}\right)$. Good perfusion of both the endocardial and epicardial halves (good/good, a, a'), good enhancement in the epicardium but only fair in the endocardium (good/fair, b, b'), and poor perfusion in both halves (poor/poor, c, c'). Arrowheads show horizontal infarct area.

distal LAD on coronary arteriography. These 20 cases were considered to have almost the same extent of horizontal risk area. The ECG in chronic phase showed that 2 cases were non-Q MI and 18 were Q-MI. The average LV ejection fraction (LVEF) after reperfusion was $51 \pm 14 \%$. Written informed consent was given by all patients before inclusion in the study.

\section{Study Protocol}

All 20 patients underwent intravenous MCE and MDCT 2 weeks after balloon reperfusion therapy and were discharged from hospital approximately 3 weeks. Follow-up coronary arteriography, left ventriculography and 2-dimen- sional (D) echocardiography were performed approximately 6 months later. The thickness of the anterior wall (the thinnest portion) was measured by 2-D echocardiography, and the wall motion was measured by both 2-D echocardiography (regional wall motion (RWM) score index) and leftventriculography (LVG) (center line method, RWM of anterior wall, SD/cord). Three cases were rejected after repeat coronary arteriography and LVG. There were no clinical events in any of the study patients during the study period. The procedures used in this study conformed to the principles outlined in the Declaration of Helsinki and the protocol was approved by the institute's ethical committee. 
$M C E$

MCE was conducted in gray-scale ultra-harmonic mode (SONOS 5500, Philips Medical Systems, Andover, MA, USA, S3 probe). The mean transmitting frequency and receiving frequency was $1.3 \mathrm{MHz}$ and $3.6 \mathrm{MHz}$, respectively. Levovist (Shering AG, Berlin, Germany) was used as the intravenous contrast agent, given by infusion device (Medrad Pulsar, Medrad Indianola, PA, USA) at a rate of $750 \mathrm{mg} / \mathrm{min}(2.5 \mathrm{ml} / \mathrm{min})$ with a concentration of $300 \mathrm{mg} / \mathrm{ml}$. MCE images were captured every 4 or 6 beats in the endsystolic phase from the apical 4-chamber view under maximum mechanical index (1.3), and recorded on MO. Echo intensity was digitally assessed to derive the peak plateau echo intensity (12.1 \pm 10.3 ). A region of interest (ROI, $\approx 300$ square pixels) was placed over the endocardial and epicardial half of the mid-septum of the anterior and lateral walls (Fig 1a) and the peak echo intensity $\left(\mathrm{AU}^{2}\right)$ at each region was measured by on-line equipped software (Quanticon, Philips) ${ }^{12}$ The subtracted peak echo intensity of the infarct lesions was calibrated using the peak echo intensity of the well-enhanced intact mid-lateral wall because myocardial enhancement by MCE varies in each patient. The ratio was scored semi-quantitatively in each area: good ( $>90 \%$ of contrast opacification of non-infarct area), fair (70-90\%), and poor $(<70 \%)$.

\section{$M D C T$}

Two weeks after the onset of AMI, 4-slice computed tomography (CT) was performed on an Aquillion (Toshiba, Tokyo) (helical pitch: 1.5) using an intravenous bolus injection of $140 \mathrm{ml}$ iodide contrast. The diagnostic resting first-pass perfusion imaging scan (arterial image) was automatically begun when the contrast enhancement reached the aortic root. The injection speed was set at $3 \mathrm{ml} / \mathrm{s}$ up to the first $100 \mathrm{ml}$ followed by $4 \mathrm{ml} / \mathrm{s}$ for the remaining $40 \mathrm{ml}$. All patients received $10 \mathrm{mg}$ propranolol orally $1 \mathrm{~h}$ before the scan if the heart rate was more than 70 beats $/ \mathrm{min}$. A ROI was placed over the epicardial and endocardial half of the infarcted mid-septum to apex and the intact mid-lateral wall (Fig 1b). The background subtracted CT values were measured in each region and the subtracted CT values of the infarct lesions were calibrated using subtracted CT values of the intact mid-lateral wall. The ratio was scored semiquantitatively as before.

\section{Statistical Analysis}

Data are presented as mean $\pm \mathrm{SD}$. Group comparisons were performed by Student's t-test or ANOVA with Bonferroni's multiple comparison post hoc test for continuous variables and chi-square test for categorical values, as appropriate. A p-value of $<0.05$ was considered to indicate a

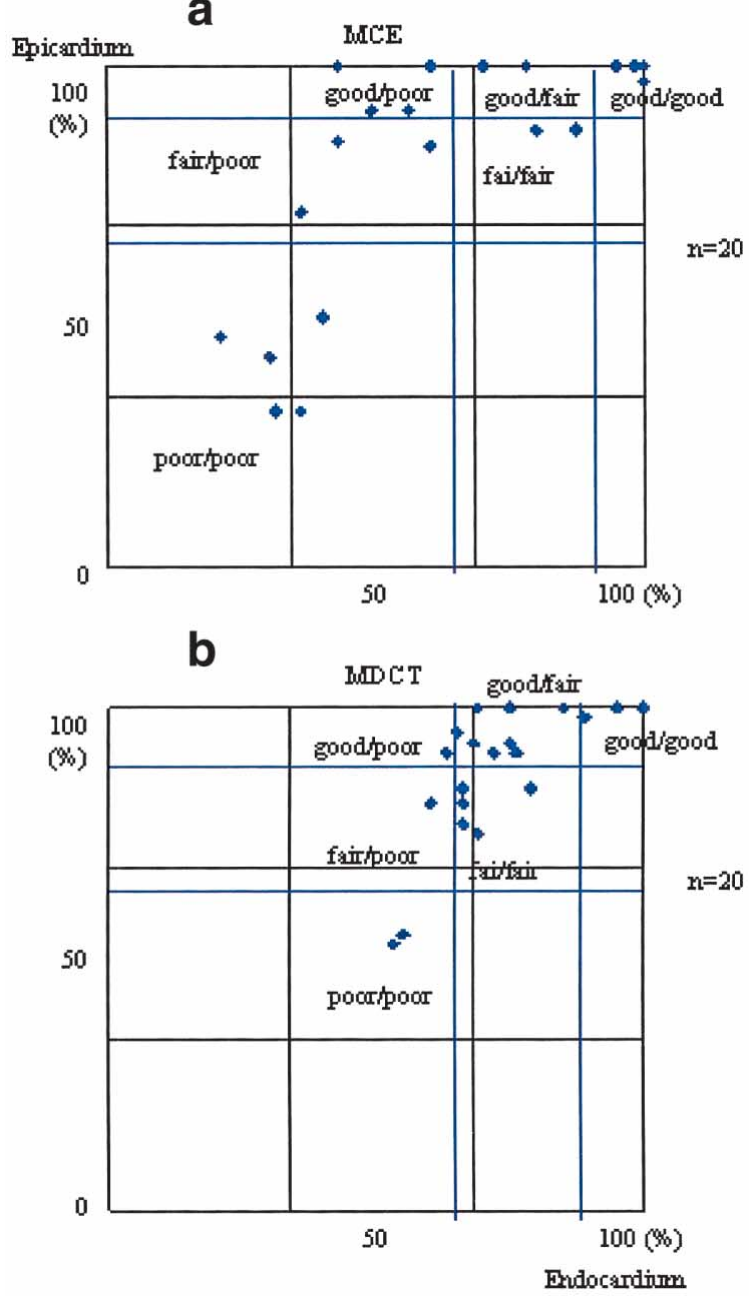

Fig 3. Evaluation of transmural perfusion by (a) MCE and (b) MDCT. The $\mathrm{x}$-axis is endocardial perfusion and $\mathrm{y}$-axis is epicardial perfusion. Blue lines are $90 \%$ and $70 \%$ perfusion of the infarcted wall calibrated by the non-infarcted lateral wall.

statistical significance.

\section{Results}

Assessment of Transmural Microcirculation by MCE and $M D C T$

Representative MCE and MDCT images are shown in Fig $2 \mathrm{a}-\mathrm{c}$. The ratio of the peak echo intensity of infarct lesion to intact wall in the epicardial half by MCE was

Table 1 Concordance of MCE and MDCT

\begin{tabular}{lcccccc}
\hline \hline \multirow{2}{*}{ epi/endo } & \multicolumn{7}{c}{ MCE } \\
\cline { 2 - 6 } & good/good & good/fair & good/poor & fair/fair & fair/poor & poor/poor \\
\hline MDCT & 2 & 0 & 0 & 1 & 0 & 0 \\
good/good & 2 & 1 & 1 & 0 & 2 & 0 \\
good/fair & 0 & 0 & 3 & 0 & 0 & 0 \\
good/poor & 0 & 0 & 0 & 0 & 2 & 0 \\
fair/fair & 0 & 0 & 0 & 1 & 0 & 3 \\
fair/poor & 0 & 0 & 0 & 0 & 0 & 2 \\
poor/poor & 0 & & & & \\
\hline
\end{tabular}

The concordance of MCE and MDCT was 80\%. chi-square $=41.1, p=0.02$.

MCE, myocardial contrast echocardiography; MDCT, multi detector computed tomography; epi, epicardial; endo, endocardial. 


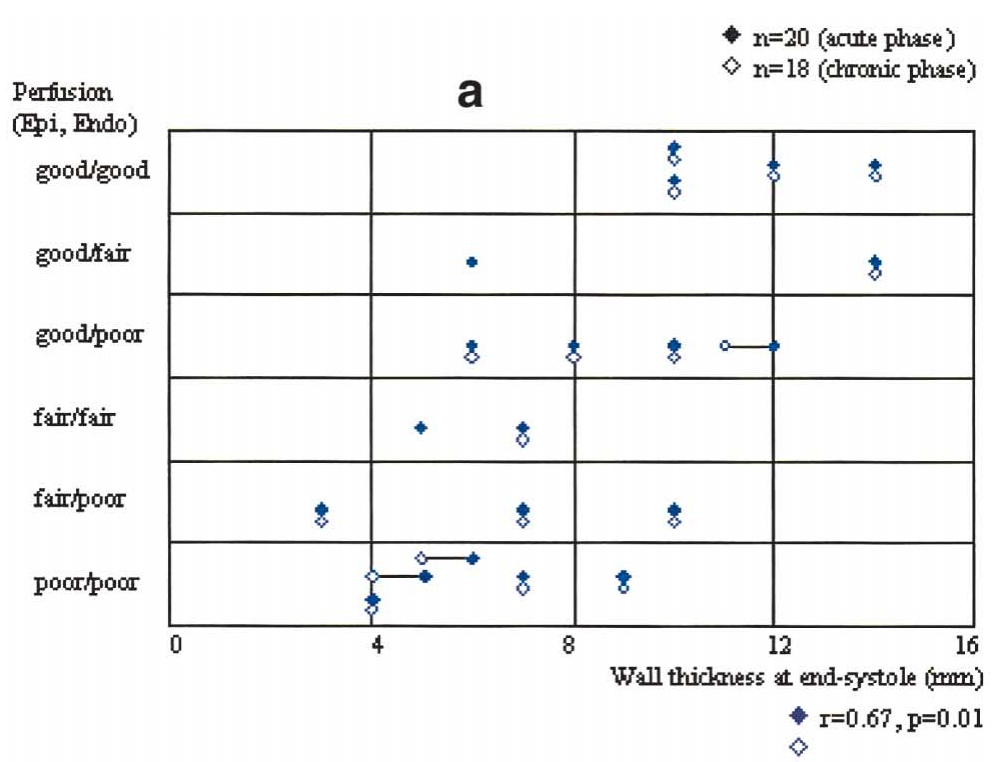

b

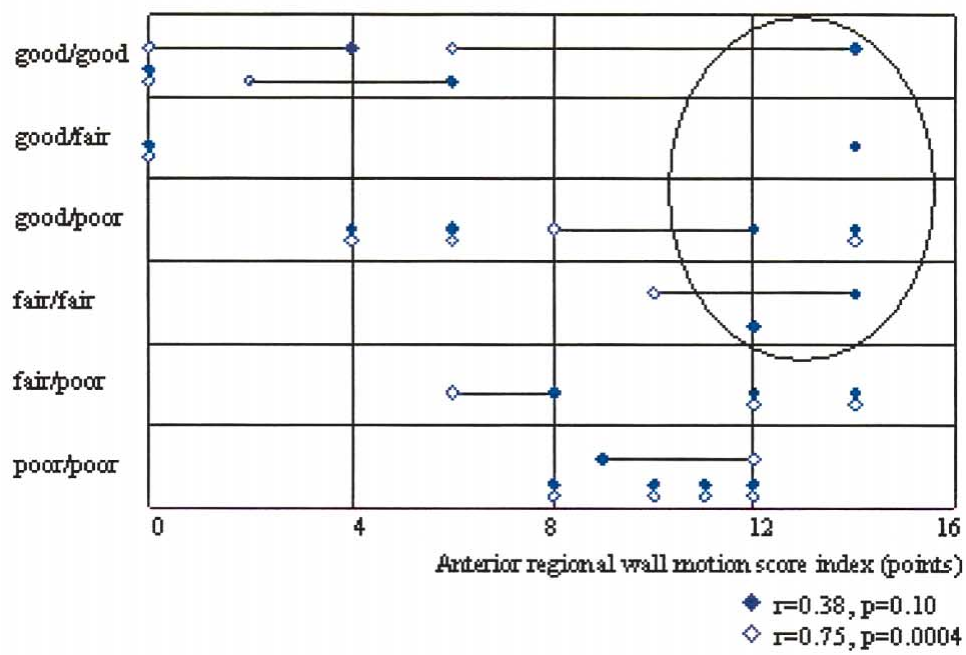

Fig 4. (a) Wall thickness and transmural perfusion. Black dots: acute phase, white dots: chronic phase. There is almost no difference in the wall thickness between acute and chronic phase. (b) Wall motion and transmural perfusion. The data in the circle are from the group in which wall motion was poor but transmural perfusion was good or fair in the acute phase. Regional wall motion score index of anterior wall, 8 segment, full score is 32 points. greater than the ratio in the endocardial half $(79.7 \pm 25.0 \%$ vs $60.7 \pm 26.1 \%, \mathrm{p}=0.01$ ). The CT number (Hounsfield (HU) units) of the infarct lesion of the epicardial and endocardial halves was $114.3 \pm 30.5 \mathrm{HU}$ and $86.3 \pm 40.1 \mathrm{HU}$, respectively. The ratio of the $\mathrm{CT}$ value of the infarct lesions to intact wall in the epicardial half was greater than the ratio in the endocardial half $(87.0 \pm 13.8 \%, 73.7 \pm 13.5 \%, p=0.002)$. There were no cases in which the perfusion of the endocardial half was greater than that of the epicardial half by MCE and MDCT (Fig 3). Assessment of transmural microcirculation by MCE corresponded to the evaluation by MDCT [rough concordance $( \pm 1)=17 / 20(80 \%)$, chi-square $=$ 41.1, $\mathrm{p}=0.02$ ] (Table 1).

\section{Wall Thickness and Transmural Perfusion by MCE}

There was a significant relation between the wall thinning of the infarcted area by 2-D echocardiography and transmural perfusion on MCE, in both the acute and chronic phase $(r=0.67, p=0.01)$ (Fig 4a), suggesting that wall thinning was greater with a transmural infarction than with a subendocardial one. But there was not any improvement in wall thickness between the acute and chronic phase.
Wall Motion and Transmural Perfusion by MCE in the Acute and Chronic Phases

Although the relationship between the wall motion of the infarcted area in the acute phase and transmural perfusion on MCE in the acute phase was not significant $(r=0.38$, $\mathrm{p}=0.10)$, it was significant in the chronic phase $(r=0.75$, $\mathrm{p}=0.0004)$ (Fig 4b). The good transmural perfusion detected by MCE, even though it was frequently associated with akinetic wall motion in the acute phase, resulted in greater recovery of wall motion in the chronic phase compared with cases showing poor transmural perfusion (Fig 5a). The LVEF (center line method) in the chronic phase was higher in the group with good perfusion of the epicardial half on MCE than in the poor perfusion group (acute $52.1 \pm 16.2 \%$ vs $49.0 \pm 13.1 \%$, chronic $63.8 \pm 10.4 \%$ vs $47.0 \pm 3.4 \%, \mathrm{p}=0.04)$. There were no differences in LV volume between the 2 groups (Fig 5b).

\section{Discussion}

Our present study shows that evaluation of transmural myocardial perfusion by intravenous MCE, as well as by MDCT, can predict the recovery of LV function in patients 
a

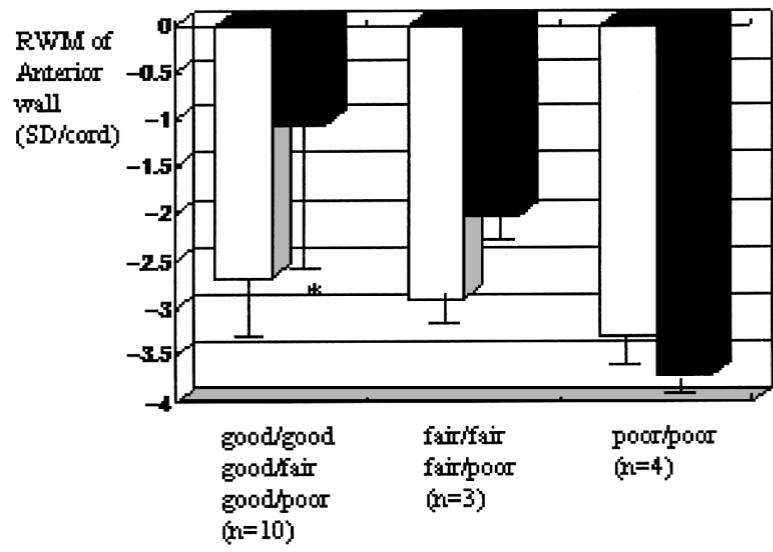

b

L VEF

(\%)

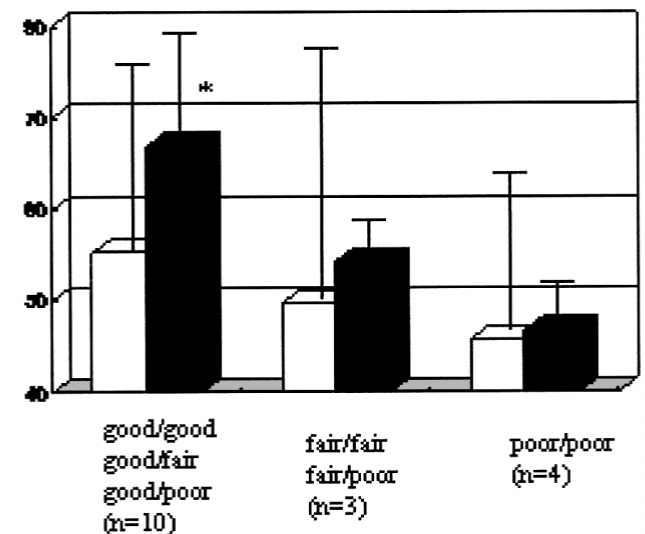

MCE perfision on 15th dxy

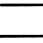

acute pluse

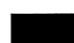

chronic phase

$* \mathrm{p}<0.05$
MCE pufiusion on 1 thth dxy
Fig 5. MCE in the acute phase and LV function. (a) MCE and RWM. (b) MCE and LVEF. SD/cord. with a reperfused AMI.

Restoration of myocardial perfusion immediately after coronary revascularization is an important mechanism for salvaging the post-ischemic myocardium5,15,16 It is also clinically important to estimate the long-term recovery of LV function of reperfused AMI. Balloon reperfusion therapy, a widespread therapeutic strategy for AMI, has increased for subendocardial infarctions vs transmural infarctions. The fact is that an AMI involving more than $20 \%$ of the subendocardium can render the myocardium akinetic despite significant subepicardial viability.

\section{Advantage of Intravenous MCE}

The high spatial resolution, quantitative analysis of perfusion and adequate timing of the assessment of perfusion are essential factors in the choice of using MCE to evaluate transmural perfusion. Experimental studies indicate that intravenous MCE can be used to assess the transmural distribution of myocardial perfusion because of its higher temporal and spatial resolution!4,17-19 Recent technical advances in MCE with intravenous drip infusion of contrast microbubbles enable assessment of the transmural distribution of myocardial perfusion in patients with significant coronary arterial stenosis ${ }^{20}$ In addition, recent clinical reports suggest that MCE may be able to differentiate stunning from necrosis and predict recovery of LV function? ${ }^{21,22}$ Ultraharmonic imaging produces low precontrast tissue signals and high post-contrast myocardial opacification, and MCE has a greater sensitivity for detecting micro- bubbles and can readily distinguish bubble signals from those generated by tissue ${ }^{20}$ Compared with harmonic power Doppler imaging, gray-scale ultraharmonic imaging provides high resolution and the ability to avoid motion artifacts.

\section{Assessment of Peak Intensity}

In their experimental study, Wei et al fitted the time intensity data to an exponential curve $\mathrm{y}=\mathrm{A}\left(1-\mathrm{e}^{-\mathrm{bt}}\right)$, where $\mathrm{A}$ is the plateau video intensity reflecting the microvascular cross-sectional area, and $\mathrm{b}$ reflects the rate of rise of video intensity and, hence, microbubble velocity? 23 The A value reflects the total volume of the capillary beds and consequently the peak intensity (A value) could be related to myocardial viability? 24,25 In a chronic ischemic pig model in which there was autologous bone marrow cell transplantation there was a linear relation between acoustic power $\left(\mathrm{AU}^{2}\right)$ and bubble density in vitro, ${ }^{13}$ and furthermore a significant linear relation between $\mathrm{AU}^{2}$ and capillary density! ${ }^{14}$ Therefore, we quantitatively assessed myocardial perfusion with MCE using the peak intensity $\left(\mathrm{AU}^{2}\right)$ to estimate the transmural extent of myocardial viability.

\section{Importance of Epicardial Perfusion}

It is considered that epicardial perfusion is important for preventing LV remodeling after AMI. Figs 3-5 show that if the perfusion of the epicardial half is preserved during the acute phase, recovery of LV wall motion can be expected. Our results suggest that the survival of subepicardial perfu- 
sion (ie, no extension of a transmural infarction) prevents long-term remodeling of the LV after AMI and contributes to the good recovery of infarcted myocardium.

\section{Advantage of Magnetic Resonance Imaging (MRI) and MDCT}

Contrast-enhanced MRI can evaluate the transmural distribution of myocardial perfusion and predict the contractile recovery of long-term global LV function after AMI26 Because of its superior spatial resolution, MDCT is an alternative tool for evaluating the transmural myocardial perfusion of congenital heart disease and reperfused AMI ${ }^{27,28}$ Our most recent study suggests that MDCT can assess transmural perfusion and predict the long-term contractile recovery after AMI8 Based on those data, we used first-pass MDCT as the golden standard for evaluating transmural myocardial perfusion in order to compare the data of MCE.

\section{Clinical Advantage and Limitation of MCE Compared With MRI and MDCT}

MCE can be conveniently done at bedside if patients cannot move because of intraaortic balloon pumping. Second, because MCE does not require exposure of radiation or iode enhancement, MCE can be safely repeated. Third, MCE can be done even immediately post stent implantation. The limitation of MCE is the difficulty acquiring good images from patients who are overweight, very thin or who have pulmonary problems.

\section{Conclusions}

Evaluation of transmural myocardial perfusion by MCE, as well as MDCT, 2 weeks after the onset of AMI can predict the long-term contractile recovery of the infarcted wall after reperfusion therapy.

\section{References}

1. Schofer J, Montz R, Mathey DG. Scintigraphic evidence of the "no reflow" phenomenon in human beings after coronary thrombolysis. $J$ Am Coll Cardiol 1985; 5: 593-598.

2. Ito H, Tomooka T, Sakai N, Yu H, Higashino Y, Fujii K, et al. Lack of myocardial perfusion immediately after successful thrombolysis: A predictor of poor recovery of left ventricular function in anterior myocardial infarction. Circulation 1992; 85: 1699-1705.

3. Ragosta M, Camarano G, Kaul S, Powers ER, Sarembock IJ, Gimple LW. Microvascular integrity indicates myocellular viability in patients with recent myocardial infarction: New insights using myocardial contrast echocardiography. Circulation 1994; 89: 2562-2569.

4. Watanabe N, Akasaka T, Toyota E, Fujimoto K, Shigeto F, Ogasawara Y, et al. Three-dimensional microstructural abnormality of the coronary capillary network after myocardial reperfusion: Comparison between reflow and no-reflow. Circ J 2004; 68: $868-$ 872.

5. Ito H, Okamura A, Iwakura K, Masuyama T, Hori M, Takiuchi S, et al. Myocardial perfusion patterns related to thrombolysis in myocardial infarction perfusion grades after coronary angioplasty in patients with acute anterior wall myocardial infarction. Circulation 1996; 93: $1993-1999$

6. Ito H, Maruyama A, Iwakura K, Takiuchi S, Masuyama T, Hori M, et al. Clinical implications of the "no reflow" phenomenon: A predictor of complications and left ventricular remodeling in reperfused anterior wall myocardial infarction. Circulation 1996; 93: 223-228.

7. Bogaert J, Maes A, Van de Werf F, Bosmans H, Herregods MC, Nuyts J, et al. Functional recovery of subepicardial myocardial tissue in transmural myocardial infarction after successful reperfusion. Circulation 1999; 99: 36-43.

8. Wada H, Kobayashi Y, Yasu T, Tsukamoto Y, Kobayashi N, Ishida $\mathrm{T}$, et al. Multi-detector computed tomography for imaging of subendocardial infarction: Prediction of wall motion recovery after re- perfused anterior myocardial infarction. Circ J 2004; 68: 512-514.

9. Senior R. Role of myocardial contrast echocardiography in the clinical evaluation of acute myocardial infarction. Heart 2003; 89: 1398 1400 .

10. Jeetley P, Swinburn J, Hickman M, Bellenger NG, Pennell DJ, Senior R. Myocardial contrast echocardiography predicts left ventricular remodeling after acute myocardial infarction. J Am Soc Echocardiogr 2004; 17: 1030-1036.

11. Yasu T. Schmid-Schönbein GW. Ultrasound contrast agents for echocardiography. Drugs Today 2000; 36: 725-731.

12. Yasu T, Greener Y, Jablonski E, Killam AL, Fukuda S, Suematsu M, et al. Activated leukocytes and endothelial cells enhance retention of ultrasound contrast micro spheres containing perfluoropropane in inflamed venules. Int J Cardiol 2005; 98: 245-252.

13. Yamada S, Komuro K, Mikami T, Kudo N, Onozuka H, Goto K, et al. Novel quantitative assessment of myocardial perfusion by harmonic power Doppler imaging during myocardial contrast echocardiography. Heart 2005; 91: $183-188$.

14. Fujii H, Tomita S, Nakatani T, Fukuhara S, Hanatani A, Ohtsu Y, et al. A novel application of myocardial contrast echocardiography to evaluate angiogenesis by autologous bone marrow cell transplantation in chronic ischemic pig model. J Am Coll Cardiol 2004; 43: $1299-1305$

15. Ikeda N, Yasu T, Kubo N, Hashimoto S, Tsuruya Y, Fujii M, et al. Nicorandil vs isosorbide dinitrate as adjunctive therapy to direct balloon angioplasty in acute myocardial infarction. Heart 2004; 90: $181-185$.

16. Kobayashi N, Ohmura N, Nakada I, Yasu T, Iwanaka H, Kubo N, et al. Further ST elevation at reperfusion by direct percutaneous transluminal coronary angioplasty predicts poor recovery of left ventricular systolic function in anterior wall AMI. Am J Cardiol 1997; 79: $862-866$.

17. Lim YJ, Nanto S, Masuyama T, Kodama K, Ikeda T, Kitabatake A, et al. Visualization of subendocardial myocardial ischemia with myocardial contrast echocardiography in humans. Circulation 1989; 79: $233-244$.

18. Linka AZ, Sklenar J, Wei K, Jayaweera AR, Skyba DM, Kaul S. Assessment of transmural distribution of myocardial perfusion with contrast echocardiography. Circulation 1998; 98: $1912-1920$.

19. Masugata H, Cotter B, Peters B, Ohmori K, Mizushige K, DeMaria AN. Assessment of coronary stenosis severity and transmural perfusion gradient by myocardial contrast echocardiography: Comparison of gray-scale B-mode with power Doppler imaging. Circulation 2000; 102: $1427-1433$.

20. Fukuda S, Muro T, Hozumi T, Watanabe H, Shimada K, Yoshiyama $\mathrm{M}$, et al. Changes in transmural distribution of myocardial perfusion assessed by quantitative intravenous myocardial contrast echocardiography in humans. Heart 2002; 88: 368-372.

21. Swinburn J, Senior R. Real-time contrast echocardiography: A new bedside technique to predict contractile reserve early after acute myocardial infarction. Eur J Echocardiogr 2002; 3: 95-99.

22. Main ML, Magalski A, Chee NK, Coen MM, Skolnick DG, Good TH. Full-motion pulse inversion power Doppler contrast echocardiography differentiates stunning from necrosis and predicts recovery of left ventricular function after acute myocardial infarction. J Am Coll Cardiol 2001; 38: 1390-1394.

23. Wei K, Ragosta M, Thorpe J, Coggins M, Moos S, Kaul S. Noninvasive quantification of coronary blood flow reserve in humans using myocardial contrast echocardiography. Circulation 2001; 103: 2560-2565.

24. Wei K, Jayaweera AR, Firoozan S, Linka A, Skyba DM, Kaul S. Quantification of myocardial blood flow with ultrasound-induced destruction of microbubbles administered as a constant venous infusion. Circulation 1998; 97: 473-483.

25. Hirata N, Shimazaki Y, Nakano S, Sakai K, Sakaki S, Matsuda H. Evaluation of regional myocardial perfusion in areas of old myocardial infarction after revascularization by means of intraoperative myocardial contrast echocardiography. J Thorac Cardiovasc Surg 1994; 108: 1119-1124.

26. Choi KM, Kim RJ, Gubernikoff G, Vargas JD, Parker M, Judd RM. Transmural extent of acute myocardial infarction predicts long-term improvement in contractile function. Circulation 2001; 104: 1101 1107.

27. Hilfiker PR, Weishaupt D, Marincek B. Multislice spiral computed tomography of subacute myocardial infarction. Circulation 2001; 104: 1083 .

28. Sugiyama H, Naito $H$, Tsukano S, Yoshibayashi M, Echigo S, Kamiya T. Evaluation by contrast-enhanced electron beam computed tomography of myocardial perfusion and tissue characteristics in congenital aortic stenosis. Circ J 2003; 67: 998-1002. 